hours (figs 4 and 5). At 48 hours one patient (case 2) showed no change but in the other the tremor was slightly worse. We assumed that this patient was not receiving enough phenylethylmalonamide and increased the dose to $400 \mathrm{mg}$ daily. After 72 hours the tremor had improved in case 1 and was only slightly worse in case 2. Phenylethylmalonamide was then stopped and tremor deteriorated. Four days later both patients were incapacitated. Phenylethylmalonamide was restarted at $300 \mathrm{mg}$ daily in case 2 and $400 \mathrm{mg}$ daily in case 1 , with rapid improvement. Phenobarbitone showed a plasma half life of 103 and 130 hours, primidone 16 hours, and phenylethylmalonamide 53 hours (nitrogen-selective gas chromatography ${ }^{5}$ ).

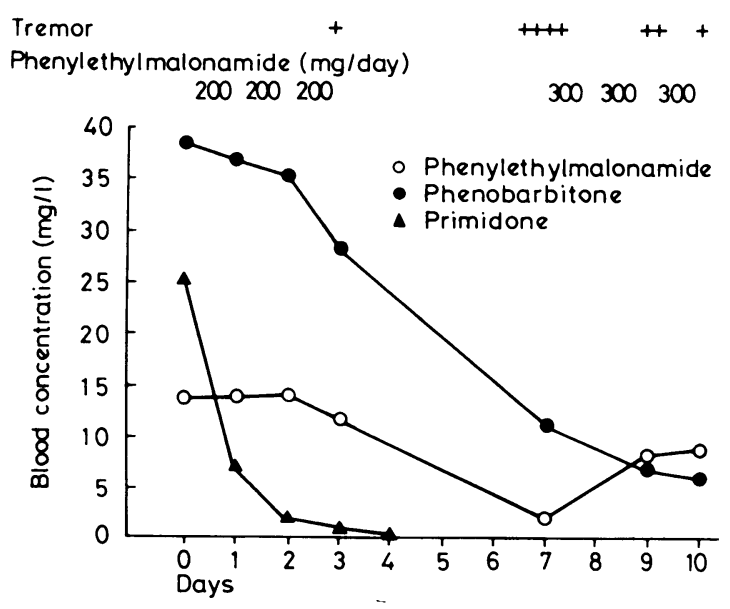

FIG 5-Case 2. Blood concentrations of primidone, phenobarbitone, and phenylethylmalonamide over 10 days.

\section{Conclusion}

Primidone is highly effective in benign familial tremor, and this effect appears to be mostly due to derived phenylethylmalonamide. Primidone itself appears to have some effect, however, since in both patients tremor deteriorated a little after stopping primidone despite a constant phenylethylmalonamide concentration in one and a rising phenylethylmalonamide concentration in the other. Primidone was more effective than propranolol and in some patients nearly as effective as alcohol. Adding propranolol resulted in some further improvement. More patients (about 30\%) with benign familial tremor were intolerant of primidone in small doses than is our clinical experience in patients with epilepsy.

We thank Desitin Verke (Hamburg) and ICI Ltd (Macclesfield) for providing phenylethylmalonamide.

Requests for reprints should be addressed to: Dr M D O'Brien, Department of Neurology, Guy's Hospital, London SE1 9RT.

\section{References}

${ }^{1}$ Gould SB. The deserts of southern France. Vol 2. London: Methuen, 1894:40.

${ }^{2}$ Critchley M. Observations on essential tremor. Brain 1949;72:133-9.

${ }^{3}$ Lasson T, Sjögren T. Essential tremor. Acta Psychiatr Neurol Scand 1960; 36:1-176.

4 Marshall J. Observations on essential tremor. $f$ Neurol Neurosurg Psychiatry 1962;25:112-25.

5 Toseland PA, Albani M, Gauchel F. Organic nitrogen detection of some anticonvulsant drugs and barbiturates in plasma and tissues. Clin Chem $1975 ; 21$ :98-104.

(Accepted 31 October 1980)

\title{
Effect of discothèque environment on epileptic children
}

\author{
T P BERNEY, J W OSSELTON, I KOLVIN, M J DAY
}

\begin{abstract}
A free-field study of 22 epileptic children, selected on the basis of past electroencephalographic abnormality, identified a group who exhibited a significant increase in epileptiform discharge rate on electroencephalography in a discothèque environment $(p<0.05)$. Laboratory investigations showed that these children were activated by a wide range of stimuli, including intermittent photic stimulation and exercise. The response to exercise was a good predictor of a child's electroencephalographic response in a discothèque.

The findings suggest that most epileptic children are not particularly vulnerable in a discothèque environment.
\end{abstract}

\section{Introduction}

The current popularity of discothèques has heightened the anxiety that loud music and flashing lights might be harmful, particularly to children with epilepsy. Consequently, some avoid discothèques, either on medical advice or because of their own or their parents' fears. This could be a social handicap.

The aims of this study were, firstly, to examine the neurophysiological effects of a simulated discothèque environment on a group of epileptic children by monitoring their electroencephalograms; and, secondly, to see whether those at risk could be identified by the use of electroencephalographic activation techniques in conventional laboratory surroundings.

\section{Patients and methods}

Twenty-two children aged 10-16 years met the criteria for admission to this study: normal intelligence and a history of epilepsy with sufficient epileptiform discharges in the electroencephalogram for changes to be measurable over short periods of time. Nearly all had suffered from generalised tonic-clonic seizures; 10 had a clinical history of photosensitivity. Fourteen avoided discothèques, nine because they had experienced discomfort when attending them.

Each recording session was in two parts: an initial electroencephalographic examination of about one hour's duration, including hyperventilation, exercise, and photic stimulation; followed by a period of about three-quarters of an hour in a simulated discothèque with other children. The electroencephalogram was recorded by radiotelemetry

Regional Medical Physics Department, Newcastle General Hospital, Newcastle upon Tyne NE4 6BE

M J DAY, BA, PHD, top-grade medical physicist 
in an adjoining observation room. The music was a selection of current popular hits; multicoloured discothèque lighting was driven by a Pulsar Zero 3000 control unit.

\section{LABORATORY SESSION}

The subjects' eyes were closed for half the duration of each of the following procedures (fig 1).

A recording at rest for 12 minutes, which provided baseline data for comparison with subsequent responses.

Hyperventilation procedure-Three minutes of overbreathing followed by five minutes' rest.

Exercise procedure-Stepping for three minutes at a rate sufficient to tire the subject, followed by five minutes' rest.

Intermittent photic stimulation using a xenon lamp (without grid) at one metre and using the frequency to which previously the child had been found most sensitive. A series of five-second bursts of intermittent photic stimulation at 20 -second intervals (to a maximum of five bursts) were given-firstly, with the eyes open, and then with them closed. This sequence was repeated while listening to pop music.

Combined activations-The hyperventilation procedure and later the exercise procedure were repeated, both with concurrent exposure to intermittent photic stimulation in the format shown in fig 1 .

A rest period with music for six minutes followed by an equal period with music and discotheque lighting combined.

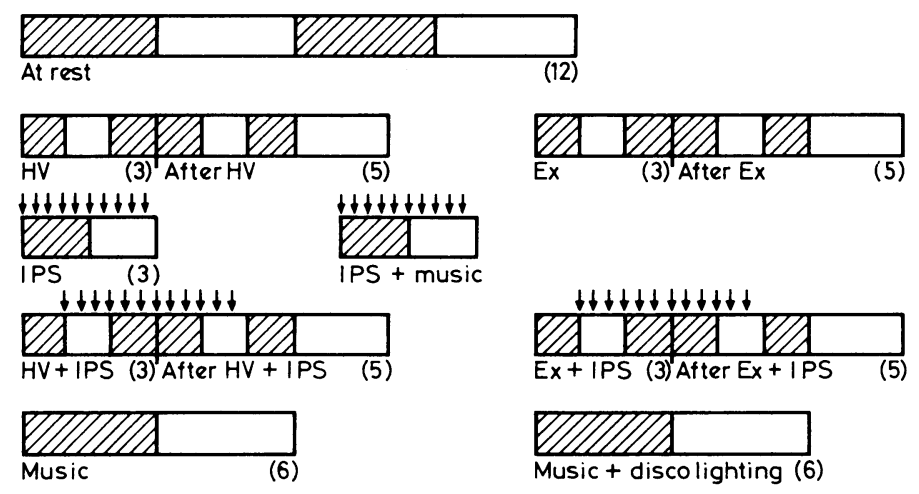

$\square$ Eyes open $\square$ Eyes closed | 5 secsIPS FIG $1-$ Schematic representation of laboratory test procedures (duration in
minutes). $\mathrm{HV}=$ Hyperventilation. Ex $=$ Exercise. IPS = Intermittent photic stimulation.

\section{DISCOTHÈQUE SESSION}

The subject joined a fairly constant group of about six children in a darkened discothèque with an observation window.

The session began with five minutes of very slowly changing discothèque lighting (independent of music). This baseline was followed by 10 minutes during which the lighting changed at the frequency used for intermittent photic stimulation in the preceding laboratory session (type A). Next came 10 minutes during which the light changes were triggered by peaks in the loudness of the music (type B); and then 10 minutes during which different colours were linked to specific frequency bands in the music (type C). For the final five minutes the room was illuminated solely by a stroboscope at 8 flashes/sec-the upper frequency limit considered safe by the Greater London Council (personal communication).

The subject's electroencephalogram and behaviour were monitored continuously throughout the afternoon. A member of staff was always near the child, and there was opportunity to rest before starting a new procedure. If the epileptiform electroencephalographic discharges became unduly frequent or prolonged, or if the subject complained of discomfort, the procedure was interrupted. If two consecutive bursts of intermittent photic stimulation evoked paroxysmal responses, that series would be discontinued.

The electroencephalographic records were examined for epileptiform discharges, which ranged from a single spike or sharp wave to a mixture of high-voltage spikes and slow waves in all channels; but for this analysis, no distinction was made between them. The changes in discharge rates between one part and another were tested for statistical significance (see Appendix), both for individuals and for groups. The overall responsiveness was scored according to the constancy of response to five bursts of intermittent photic stimulation.

TABLE I-Characteristics of groups of 22 children studied

\begin{tabular}{lcc}
\hline & $\begin{array}{c}\text { Groups 1 and 2 } \\
(\mathrm{n}=16)\end{array}$ & $\begin{array}{c}\text { Group 3 } \\
(\mathrm{n}=6)\end{array}$ \\
\hline Male & 12 & 1 \\
Female & 4 & 5 \\
Electroencephalographic discharges: & 1 & 5 \\
$\quad \begin{array}{l}\text { Primary generalised } \\
\text { Multifocal }\end{array}$ & 12 & 1 \\
Focal & 3 & \\
Medication (and control): & & $1(1)$ \\
Phenobarbitone/phenytoin & $9(5)^{*}$ & $5(5)$ \\
Sodium valproate & $2(2)$ & \\
\hline
\end{tabular}

*Figures in parentheses are numbers of children with effective seizure control.

\section{CLASSIFICATION}

Three groups were identified (table I).

Group 3-Six of the 22 children had so few epileptiform discharges, both in the laboratory and in the discothèque sessions, as to be distinct from the remainder. They also differed significantly in being clinically well controlled on valproate $(p<0.02)$, being predominently girls $(p<0.05)$, and in having primary generalised epilepsy $(p<0.05)$.

Of the 16 remaining children, who formed the basis of the study, most showed reasonably frequent multifocal or generalised epileptiform discharges. They were subdivided as follows by their response in the discothèue setting.

Group 2 were 10 children who showed little change or a decrease in the incidence of their electroencephalogram discharges.

Group 1 were six children who showed a statistically significant increase in the incidence of discharges during at least one of the periods of discothèque lighting (type $\mathrm{A}, \mathrm{B}$, or $\mathrm{C}$ ).

We describe the findings in groups 1 and 2 .

\section{Results}

\section{LABORATORY PROCEDURES}

We examined the responses of groups 1 and 2 to the laboratory procedures to see whether they were consistent with the classification and whether they could be used to predict an individual's response to the discothèque.

Eye closure at rest-While voluntary closure on command did not discriminate between groups 1 and 2, nine children showed an increase in discharge rate which appeared more prolonged than the few seconds described by Jeavons and Harding. ${ }^{1}$ This suggests an activating effect, maximal on eye closure and decreasing at a variable rate over one to two minutes.

Hyperventilation procedure-The activating effect of this procedure (particularly during hyperventilation) was shown by a significant increase in the discharge rates in both groups, though there was no distinction between them.

Exercise procedure-Group 1 showed a highly significant increase in discharge rate, both during exercise and during the after-exercise recovery period. In contrast, group 2 showed only a slight increase.

When the procedure as a whole (including the exercise and recovery periods) was compared with the resting baseline, five of the six children in group 1 showed a significant increase. This was not found in any of the children in group 2 . The difference between these proportions was highly significant ( $\mathrm{p}=0.003$; exact probability test).

Intermittent photic stimulation-With their eyes open, all six subjects in group 1, but only four of the 10 in group 2 , had a definite paroxysmal response to intermittent photic stimulation. This difference was just short of significant $(p=0.052)$. All but one of the 16 children in the two groups, however, showed paroxysmal responses to intermittent photic stimulation when this was performed concurrently with hyperventilation. Intermittent photic stimulation with concurrent exercise showed a similar picture.

Rest period with music and disco lights-Adding music produced a significant increase in discharges in group 1 and, if anything, a decrease in group 2. The further addition of disco lighting did not make a significant difference. 


\section{DISCOTHÈQUE}

As expected from the classification used, group 1 showed greater increases in discharge rates than group 2 and all of the differences from the baseline proved significant. The graphs of the averages for each group, in both the laboratory and the discothèque settings (fig 2), suggest that these increments might be progressive and related to the increasing complexity of environmental stimuli. Group 1 showed a substantial increase with music, which flattened off until the periods with types $\mathrm{A}, \mathrm{B}$, and $\mathrm{C}$ lighting in the discothèque setting. As might be expected, there was then a further increase but this change was not significant; nor were the differences produced by the various types of discothèque lighting significant. The use of stroboscopic illumination, however, produced a further, highly significant increase $(p<0.01)$.

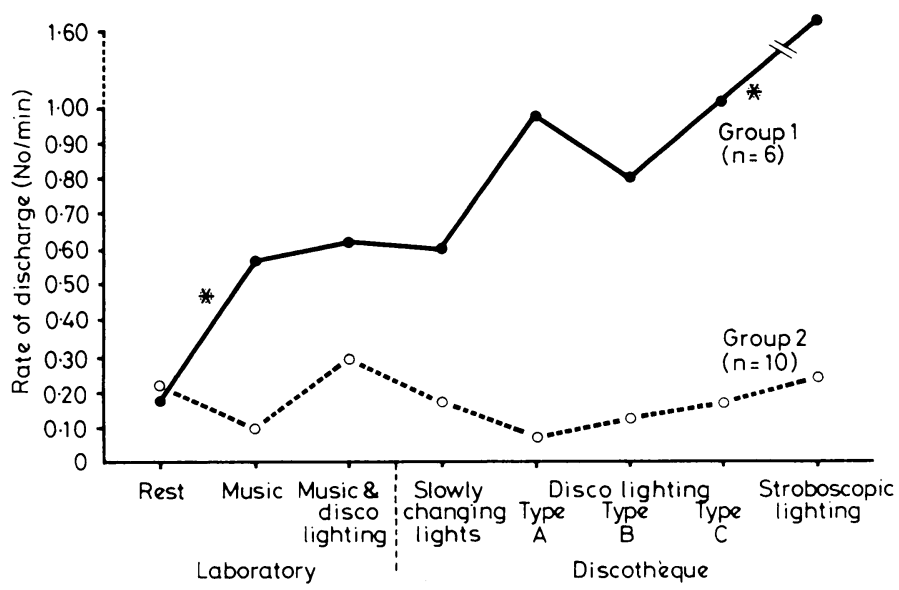

FIG 2-Average rates of epileptiform discharges during laboratory and discothèque procedures. $\left({ }^{*} \mathrm{p}<0.05\right.$.)

TABLE II-Temporal distribution of epileptiform discharges in one subject at rest and during relaxation with music and lights (both with eyes closed)

\begin{tabular}{lcc}
\hline & At rest & Music and lights \\
\hline No of discharges & 20 & 44 \\
Mean interval \pm SD between discharges (seconds) & $16 \cdot 2 \pm 15 \cdot 4$ & 4.55 .4 .02 \\
Goodness of fit $\left(\chi^{2}\right)$ & $0.41(3 \mathrm{df})$ & $9.27(6 \mathrm{df})$ \\
p Value & 0.94 & $0 \cdot 16$ \\
\hline
\end{tabular}

\section{Discussion}

There are several possible explanations for the rarity of reported epileptic seizures in a discothèque environment: ictal phenomena may not be recognised as such, particularly if modified by medication or masked by excited crowd behaviour. One of the children showed just such unnoticed seizures which once highlighted by a coincident electroencephalographic discharge became clinically obvious.

Alternatively, those who have had an earlier indication of their vulnerability, such as photosensitivity or discomfort in discothèques, might deliberately avoid them. In this study it was notable that the degree of clinical control and the attitude towards a discothèque related neither to each other nor to whether a child was in group 1 or group 2 . Of the six children so effectively controlled as to be distinct from the rest (group 3), three had an aversion to discothèques. These had had clinical seizures provoked by photic stimuli before the start of medication. As they had subsequently avoided discothèques, they would not have had an opportunity to unlearn any aversion they might have developed initially.

A third explanation might be that, for most, the effect of provocative stimuli might be offset by other factors in the environment. Exercise has been suggested as having just such a normalising or protective effect. ${ }^{2-1}$ Our study suggests that, although this might apply to most epileptics, there are some who are activated by exercise and, even more effectively, by the period of rest immediately afterwards. When both components are taken into account, as in our exercise procedure-taking the last two minutes of exercise and the first two minutes of the ensuing recovery period-a significant increase in discharge rate, in comparison to a rate at rest, identifies these rather labile epileptics. Their responses indicate that they are consistently susceptible to a wide range of disparate stimuli: voluntary eye closure, music, hyperventilation, and intermittent photic stimulation as well as conventional discothèque lighting. In the discothèque they are particularly susceptible to stroboscopic illumination even at a relatively low, and generally accepted, frequency.

In view of the selection criteria applied (that the child was likely to show epileptiform discharges in the electroencephalogram), not surprisingly the degree of seizure control was poor in a third of the children studied. Only a quarter of the children (group 1), however, showed a substantial increase in discharge rate in the discothèque. Although a wider sample would be necessary for confirmation, apparently only a small minority of epileptics are likely to be adversely affected in a discothèque.

The co-operation of the children was essential, and we acknowledge the considerable time and skill put into the study by Mrs Ann Palmer and Mrs Yvonne Hewitt, the senior physiological measurement technicians.

\section{Appendix}

\section{BASIS OF STATISTICAL ANALYSIS}

Experimental data-The data consisted of the numbers of epileptiform electroencephalographic discharges (typically 0-30) observed over definite intervals (3-30 minutes) under control conditions and also with various stimuli. There was no replication. Because of the small number of discharges observed for any one subject with a particular stimulus, any estimate of discharge rate was unavoidably subject to large random error. It was necessary to estimate this error and take it into account in testing the statistical significance of any apparent response to a stimulus.

Statistical model-Since there was no replication, information on the degree of random variation was obtained by studying the distribution of discharges in time. The simplest theoretical model is one in which the discharges occur independently with constant probability density. The interval between successive discharges will then be exponentially distributed. A subject with relatively high discharge rates was selected for study in terms of this model (table II). The goodness-of-fit test and the fact that the SD was approximately equal to the mean showed that the data were compatible with the expected exponential distribution. The same model implies that the number of discharges in a given period would be Poisson distributed, and this was taken as the basis for statistical analysis.

Statistic for testing apparent change in discharge rate-Suppose that $\mathrm{D}_{1}$ discharges occur in time $\mathrm{t}_{1}$ under "control" conditions and $\mathrm{D}_{2}$ discharges in time $t_{2}$ under "experimental" conditions. A statistic for testing the apparent change in discharge rate $\left(D_{1} / t_{1}\right.$ to $\left.D_{2} / t_{2}\right)$ is given by

$$
\mathrm{u}=\frac{\mathrm{D}_{1} \mathrm{t}_{2}-\mathrm{D}_{2} \mathrm{t}_{1}}{\left(\mathrm{D}_{1} \mathrm{D}_{2}\right) \mathrm{t}_{1} \mathrm{t}_{2}}
$$

On the null hypothesis $u$ has zero expectation and unit variance. Its exact distribution has been computed. For approximate calculation of $p$ values we find that the assumption of normality is rarely misleading even if $D_{1}$ and $D_{2}$ are extremely small.

\section{References}

${ }^{1}$ Jeavons PM, Harding GFA. Photosensitive epilepsy. London: Heinemann, 1975.

2 Götze W, Kubicki St, Munter M, Teichmann J. Effect of physical exercise on seizure threshold. Dis Nerv Syst 1967;28:664-7.

${ }^{3}$ Livingston S, Berman W. Participation of epileptic patients in sports. FAMA 1973;224:236-8.

4 American Medical Association Committee on the Medical Aspects of Sports and the Committee on Exercise and Physical Fitness. Convulsive disorders and participation in sports and physical education. $\mathcal{F} A M A$ $1968 ; 206: 1291$.

(Accepted 19 November 1980) 